\title{
ENABLING TECHNOLOGIES FOR THE PREPARATION OF MULTIFUNCTIONAL "BULLETS” FOR NANOMEDICINE
}

\author{
Martina K, Serpe L, Cavalli R, Cravotto G凶
}

Department of Drug Science \& Technology,

Centre for Nanostructured Interfaces and Surfaces (NIS), University of Turin, Turin, Italy

Recent advances in nanotechnology, including modern enabling techniques that can improve synthetic preparation and drug formulations, have opened up new frontiers in nanomedicine with the development of nanoscale carriers and assemblies. The use of delivery platforms has attracted attention over the past decade as researchers shift their focus away from the development of new drug candidates, and toward new means with which to deliver therapeutic and/or diagnostic agents. This work will explore a transdisciplinary approach for the production of a number of nanomaterials, nanocomplexes and nanobubbles and their application in a variety of potential biological and theranostic protocols. Particular attention will be paid to nanobubbles, stimuli responsive nanoparticles and cyclodextrin grafted nanosystems produced under non-conventional conditions, such as microwave and ultrasound irradiation. Besides nanoparticles preparation, ultrasound can also act as an enabling technology when activating sensitive nanobubbles and nanoparticles.

Keywords: nanoparticles, nanobubbles, stimuli responsive, ultrasound, microwave

Funding: the University of Turin is warmly acknowledged for their financial support (Ricerca Locale 2017).

$\triangle$ Correspondence should be addressed: Giancarlo Cravotto

Via P. Giuria 9, Turin, Italy, 10125; giancarlo.cravotto@unito.it

Received: 26.06.2018 Accepted: 30.08.2018

DOI: $10.24075 /$ brsmu.2018.082

\section{ИСПОЛЬЗОВАНИЕ ПЕРЕДОВЫХ ТЕХНОЛОГИЙ ДЛЯ НАНОМЕДИЦИНЫ: ПОЛУЧЕНИЕ МНОГОФУНКЦИОНАЛЬНЫХ «ВОЛШЕБНЫХ ПУЛЬ»}

\author{
К. Мартина, Л. Серпе, Р. Кавалли, Д. Кравотто
}

Кафедра фармацевтических технологий,

Центр наноструктурированных интерфейсов и поверхностей, Туринский университет, Турин, Италия

\begin{abstract}
Недавние достижения в области нанотехнологии, в том числе современные методы, позволяющие усовершенствовать способы приготовления лекарственных средств, открыли новые горизонты в наномедицине, связанные с разработкой наноразмерных средств доставки лекарственных препаратов и целых комплексов. Последнее десятилетие большое внимание уделяется использованию нанопереносчиков - усилия исследователей направлены не столько на разработку новых препаратов, сколько на поиск способов целевой доставки терапевтических и/или диагностических агентов. В работе рассмотрены трансдисциплинарный подход к получению наноматериалов, нанокомплексов, нановезикул и перспективы их применения в биологии и тераностике. Особое внимание уделено получению нанопузырьков, стимулчувствительных наночастиц (НЧ) и наносистем с привитым циклодекстрином при нестандартных условиях, таких как действие ультразвука (УЗ) и микроволнового излучения. Помимо использования в процессе приготовления НЧ, УЗ можно так же эффективно применять для активации чувствительных нановезикул и НЧ.
\end{abstract}

Ключевые слова: наночастицы, нанопузырьки, стимулчувствительный, ультразвук, микроволновое излучение

Финансирование: авторы признательны администрации Туринского университета за их финансовую поддержку (Ricerca Locale 2017).

$\varangle$ Для корреспонденции: Джанкарло Кравотто

ул. Р. Giuria, д. 9, Турин, Италия, 10125; giancarlo.cravotto@unito.it

Статья получена: 26.06.2018 Статья принята к печати: 30.08.2018

DOI: 10.24075/vrgmu.2018.082

Engineered nanomaterials can be made from nearly any substance; carbon based nanomaterials, natural and synthetic polymers, silica, metal and metal oxides can all be used, just as lipophilic colloidal nanoparticles (NP) can be made from solid lipids and phospholipids. In the field of bionanotechnologies, nanomaterials are used for biomedical applications, including as drug carriers, contrast agents and biosensors. Many of the properties that make nanomaterials useful may also be responsible for toxicity to cells and organisms. Their high surface area, in fact, allows them to be more readily reactive and easily transported through environmental barriers, cellular membranes and throughout the body. Attention must be paid to safety issues and a rational, science-based approach to nanotoxicology must be undertaken if the full potential of nanotechnologies is to be realised.

A number of different approaches to NP preparation have been attempted over the years, with both conventional and non-conventional methodologies being used in the solid and liquid phases [1]. Producing NPs that are homogeneous in their size and shape distributions is paramount and a number of techniques have been tested for their ability to accomplish this task; mechanochemistry has been used in solvent-free, solid-phase protocols, while microwave (MW) and ultrasound (US) irradiation have mostly seen use in aqueous solution syntheses. MW radiation can produce high quality NPs in short time periods because it is an efficient heating source. Moreover, 
sonochemical irradiation produces high mixing uniformity and a reduction in crystal growth, which can also lead to an acceleration in chemical dynamics effects and reaction rates. It can therefore be considered one of the most powerful tools in nanostructured material synthesis [2, 3].

Experience in sonochemistry and MW-assisted syntheses has been beneficial to the derivatization of carbon-based nanomaterials as well as to the production of nanostructured cyclodextrin (CD) oligomers and CD-grafted nanomaterials for biomedical applications. CD derivatives have been shown to host drugs and contrast agents and can thus act as versatile and efficient carriers and contrast agent for MRI. Furthermore, the grafting of CDs onto NPs increases their water solubility, surface accessibility and hosting capability. Nanobubbles (NBs) are spherical core/shell structures and innovative nanoplatforms upon which to develop multifunctional nanocarriers for targeted imaging and therapeutic applications. In the field of cancer medicine, nanosystems with stimuli-responsive features have attracted a great deal of attention because of their enhanced cancer drug targeting.

Interestingly, these nanodelivery strategies can all have a key role to play in the success of a therapy as they can provide "on demand release" and "personalized treatment". These ideas can be exploited even further by applying the concept of "the right drug for the right person in the right moment". This review highlights the current state and future prospects of smart drug delivery systems that benefit from their responses to specific internal (e.g., variation in redox gradient) and external (e.g., light, US and magnetic field) triggers.

\section{Cyclodextrin-based or grafted nanomaterials}

The use of nanotechnology for drug delivery applications provides new opportunities and may change the landscape of the pharmaceutical and biotechnology industries as the goal of targeted drug delivery, the delivery of drugs to intracellular targets and the monitoring of drug delivery sites (theranostics), comes ever closer. CDs can play a crucial role in the achievement of such challenging goals as they are biocompatible and are wellknown to improve the physicochemical properties of drugs (stability, solubility and bioavailability) [4]. Non-conventional US and MW irradiation have seen widespread use, besides a variety of other synthetic methods, in the production of novel and known CD-based structures and have done so with high efficiency and in short reaction times.

A water-soluble oligo CD heterononamer has been synthesized under US irradiation for use as a dendrimeric multicarrier with high hosting ability. Its applicability as an MRI contrast agent was demonstrated via the relaxometric titration of $\mathrm{Gd}$ complexes placed within the dendrimeric platforms, as well as by cell viability and binding affinity experiments, which all gave excellent results [5].

CD can be efficiently grafted onto silica under conventional and non-conventional conditions [6, 7] (Fig. 1), while this hybrid system's ability to absorb organic molecules has been extensively studied and applied. An interesting example of dual-pore silica NPs has been investigated by J.-H. Lee et al. as efficient therapy for gene-chemo cancer. The positively charged larger pore was loaded with negatively charged siRNA and the smaller pore was loaded with doxorubicin, capped by 1-adamantanthiol and a CD complex [8].

A one-shot approach to the derivatization of carbon nanotubes (SWCNT) with CDs and contrast agents has been successfully performed under MW irradiation [9]. The efficiency of MW has also been exploited for the preparation of porphine grafted graphene oxide [10].

The capacity of CDs to include/release drugs in the field of magnetic NPs has been studied. Iron oxide NPs and Au nanoroots were modified with CD-conjugated ethylenediaminefunctionalized poly(glycidyl methacrylate) with the aim of obtaining a multifunctional theranostic nanoplatform [11]. Magnetic NPs were efficiently coated with $\beta-C D$ under US irradiation to provide an increase in magnetization, which was likely due to the high crystallinity of the system produced [12].

\section{Nanobubbles: a versatile tool for biomedical applications}

NBs are another valuable platform, one of the nanotechnologybased "bullets", that is sensitive to physical external triggers and that has been proposed for imaging and therapeutic applications.

NBs derive from microbubbles, which are currently used in clinical practice as US contrast agents, but have nanoscale sizes. This feature offers some advantages, such as their extravasation from blood vessels into surrounding tissues, which improves imaging and delivery efficiency. In particular, this capability allows tumour tissues to be passively targeted via the Enhanced Permeability and Retention (EPR) effect that favours their local accumulation over long time periods. In addition, they can be triggered by US to enhance their acoustic and targeting properties. Indeed, NBs can be used as therapeutic cavitation nuclei for US-induced sonoporation, leading to the formation of transient pores in plasma membranes and the modification of cell permeability [13].

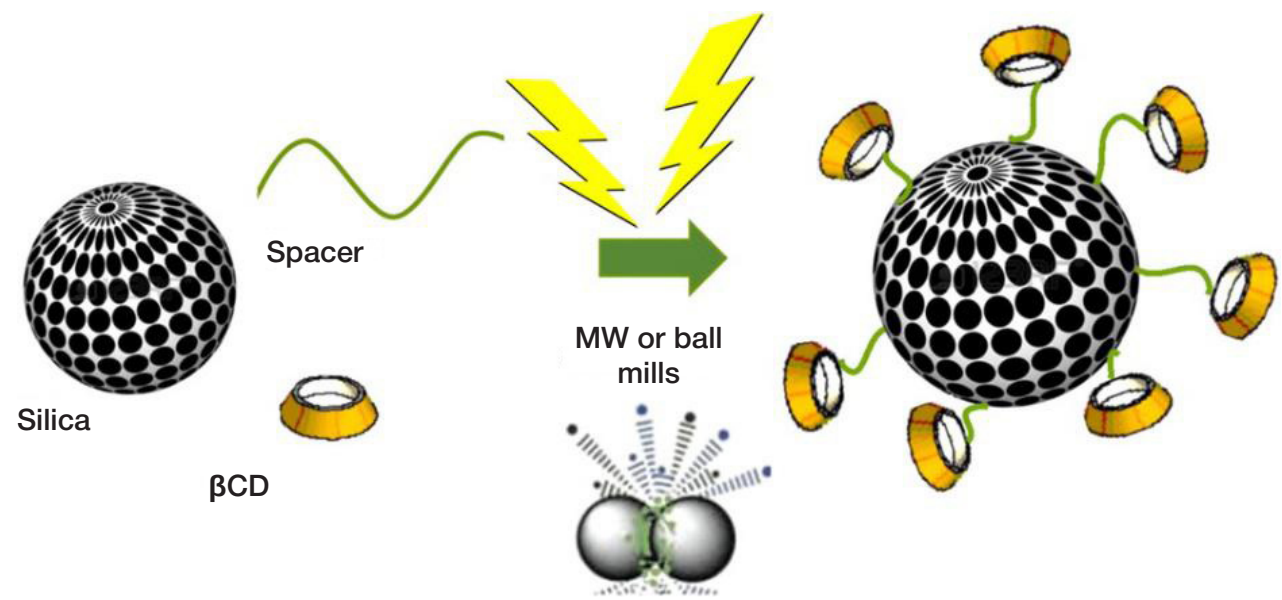

Fig. 1. Schematic representation of cyclodextrin grafted silica prepared under unconventional conditions [6]. Reprinted (adapted) with permission from (Martina K, Baricco F, Berlier G, Caporaso M, Cravotto G. ACS Sustainable Chem. Eng. 2014;2(11):2595-603). Copyright (2018) American Chemical Society) 
They can be described as spherical core/shell structures that are filled with gases or vaporizable compounds, such as perfluorocarbons, sulfur hexafluoride, air or carbon dioxide [14]. The core is a single inner chamber that makes up the largest part of a particle's volume. The use of suitable core components is crucial since composition can affect both structural and functional behaviour. The use of gases that are insoluble in water for the core (e.g. perfluorocarbons) reduces the dissolution rate of the gas from the core into the external environment, enhancing the shelf life of the systems. The compressibility characteristics of the gas core can have a significant effect on system volumetric oscillations due to the compression and rarefaction cycles of US. The bubble volumetric oscillation can facilitate backscatter echoes and drug release, which can be useful for diagnostic imaging and therapeutic applications, respectively.

The composition of the shell determines the stiffness of the bubbles, their resistance to rupture in the US pressure field, recognition by the reticuloendothelial system and their biodistribution [15]. The shell generally consists of lipids (phospholipids, cholesterol), polymers (Pluronic, polysaccharides, PLGA) or proteins (albumin).

A great deal of research has been focused on a number of NB architectures and related compositions, among these we can find polysaccharide-shelled perfluorocarbon-cored NB that have provided some interesting results [16]. They are polymer/lipid hybrid systems that have been purposely tuned to overcome NB stability issues and to improve drug-loading capability. Moreover, the presence of the polysaccharide shell means that functionalization with specific target ligands is possible.

These hybrid systems contain a phospholipid monolayer at the NB interface that can interact with polyelectrolytes. The formulation design of the hybrid lipid/polymer system was based on the knowledge that phospholipid monolayers can adsorb charged polymers, such as polysaccharides, via various types of attraction, including both electrostatic and hydrophobic interactions.

A number of manufacturing approaches have attempted to reduce bubble size. Most of these involve post-formulation microbubble manipulation, such as gradient separation by gravitational forces, physical filtration or floatation. Another approach to achieving this aim, however, is the ab initio formulation of nanoscaled systems. In this approach, NBs are mainly prepared by sonication, high shear emulsification, thinlayer evaporation and mechanical agitation; procedures that have also been used in microbubble preparation [13].

NB technology is a versatile tool for the development of externally-triggered nanocarriers that provide controlled payload release with imaging properties.

Interestingly, NBs show good drug-encapsulation efficiency and prolonged-drug release kinetics. Table 1 reports a list of bioactive molecules that have been loaded into polysaccharideshelled, perfluorocarbon-cored NB formulations using various loading methods.

\section{Stimuli-responsive nanosystems}

The efficiency of pharmacological treatment is strongly dependent on the success rate with which the active compound reaches the target site. Indeed, there are numerous challenges that a drug has to tackle before achieving its objective; enzyme attack, difficulty in accessing the target area and target-cell selectivity in competition with other sites. NP-based drug delivery systems (DDS) are therefore a promising strategy with which to face these issues, as nanotechnology has shown great improvements in target-specific drug delivery thanks to advances in passive and active targeted-drug delivery. Moreover, new additional properties that can be included within the NP-based DDS and that can enhance drug bioavailability at the disease site are very promising.

Conventional NP-based DDS ensures that the drug will not freely extravasate during blood circulation, but only be released at the target where the NPs accumulate, via either a passive or active targeting strategy. The passive strategy relies on the enhanced permeability and retention (EPR) effect that is observed in some pathological tissues. For instance, the accumulation of NPs in tumour tissue is much faster than in other tissues and is characterized by uneven distributions and particle-size dependency. On the other hand, active drug targeting takes advantages of specific target area features by decorating a NP-based DDS with monoclonal antibodies or bioconjugates [17].

However, these conventional NP-based DDSs are often accompanied by systemic side effects that are related to their non-specific biodistribution and uncontrollable drug release characteristics. There are already several NP-formulations of anticancer drugs on the market, including Doxi ${ }^{\circledR}$ and Abraxane ${ }^{\circledR}$, which have shown improved safety profiles as compared to free-drug formulations. However, drug bioavailability at the tumour is still quite low which leads to insufficient improvements in therapeutic activity [18].

Advanced controlled NP-based DDSs are being developed to achieve drug release at target sites in a spatio-temporally controlled manner, and thus overcome these limitations. The fusion of engineered nanomaterials and pharmaceutical research is paving the way for the development of innovative nanoplatforms, especially for cancer treatment, where nanomaterials can add further functionality to the loaded drug and play a crucial therapeutic role. Well-defined nanosystems can increase drugtargeting efficacy and reduce side effects by taking advantage of responses to specific internal or external triggers, giving rise to socalled "smart" or stimuli-responsive nanosystems [19].

Table 1. Examples of bioactive molecules loaded into NB formulations

\begin{tabular}{|l|l|l|}
\hline \multicolumn{1}{|c|}{ Therapeutic Applications } & \multicolumn{1}{c|}{ Loaded Drugs } & \multicolumn{1}{c|}{ Administration Routes } \\
\hline Anticancer & Doxorubicin, paclitaxel, docetaxel, cisplatin & Parenteral \\
\hline Antibacterial & Vancomycin, erithromycin & Topical \\
\hline Antifungal & Itraconazole & Topical \\
\hline Antiviral & Acyclovir, valacyclovir & Topical \\
\hline Anti-Inflammatory & Prednisolone & Parenteral \\
\hline Gene Therapy & DNA, si RNA & Parenteral \\
\hline Hypoxia-Associated Pathology & Oxygen & Parenteral/Topical \\
\hline Theranostic System & Gd Complexes & Parenteral \\
\hline Others & Curcumin, melatonin & Parenteral/Topical \\
\hline
\end{tabular}


There are a number of stimuli-responsive nanosystems that we can primarily distinguish; i) those that recognize changes in the biological milieu and thus modulate the drug-release rate as closed-loop systems related to disease features (internal triggers, such as variations in $\mathrm{pH}$, redox gradient, temperature and substance concentrations), and ii) those that switch drug release on as a function of specific external triggers and thus operate as open-loop systems that can provide pulsed drug release when externally activated (external triggers such as light, US, temperature, magnetic field and high energy radiation).

Sensitiveness to internal or external stimuli can be achieved using nanomaterials (mostly polymers) that bear functional groups that are able to modify their properties as a function of the intensity of the signal, which results in changes in DDS features, such as the ability to release the drug. These changes can have different levels of complexity, but only when these structural changes are reversible and proportional to the stimulus intensity can the NP-based DDS be considered "smart". When the target cells are those of a tumour, these requirements can be summarised in the 2R2S features, i.e. drug retention in blood circulations versus release in tumour (2R) and stealthy in blood versus sticky in tumour (2S) [18].

\section{Nanosystems that are responsive to internal stimuli}

\section{1. $\mathrm{pH}$ responsive NPS}

One typical example of internal-stimuli responsive nanosystems can be found in $\mathrm{pH}$-responsive nanocarriers for solid tumour targeting. The low $\mathrm{pH}$ that exists in the tumour extracellular matrix, caused by a high rate of glycolysis, can be used as a specific stimulus. Surface charge switchable polymeric nanosystems have been designed to enhance tumour drug delivery, as surface charge is pivotal for cell uptake. Indeed, positively charged NPs display significant cellular uptake thanks to electrostatic interactions with cell membranes. Moreover, positively charged NPs are capable of acting as "proton sponges" that disrupt lysosomes, enhance cytoplasmic delivery and induce cancer-cell death [20].

A new tetraglucose-based biomaterial, made up of cyclic nigerosyl-1-6-nigerose (CNN), has been produced by Caldera et al. A cross-linking reaction with pyromellitic dianhydride formed solid NPs, called nanosponges (NS). This new nanomaterial is biocompatible and able to swell in response to the $\mathrm{pH}$ value. Doxorubicin was incorporated to a good extent and released with very slow and constant kinetics. Interestingly, local pH plays a role in controlling the release profile of the drug. The $\mathrm{pH}$-dependent and prolonged-release kinetics of doxorubicin from CNN-NS and their enhanced anticancer activity mean that doxorubicin-loaded CNN-NS acted as a nanomedicine tool for local tumour treatment and did so with a favourable toxicology profile [21].

Interestingly, fluorescent CD derivatives have been used as acid-sensitive gatekeepers to block silica mesopores and have undergone successful doxorubicin release studies. This system presents the significant advantage of operators being able to trace the NP pathways using the green fluorescence and thus monitor therapy process [22].

\subsection{Redox responsive NPs}

The design and fabrication of redox responsive NPs is another promising means of targeting specific tumour intracellular sites. Glutathione (GSH) reduction is a well-known redox system that operates within cancer cells, which has led to GSH-responsive nanocarriers being proposed for targeted intracellular anticancer drug release. Indeed, GSH levels within cancer cells are 100 to 500 times higher than normal ranges [23]. It is well known that intracellular GSH can trigger thiol-disulfide bond exchange. Polymers with disulfide bonds can make use of this property to facilitate rapid release from carriers when stimulated by GSH. In general, there are two ways that disulfide bonds can be used in polymer systems; a) via modification of the disulfide bond on the backbone, and b) via the use of disulfide bonds as crosslinkers within the polymeric network.

Daga et al. have tuned nanosponge-based drug delivery systems to be bioresponsive to GSH for rapid nanosystem destabilization inside cells. The disulfide bridge remains stable in extracellular fluids for long periods before being reduced upon internalization within the cytosol. This improves drug bioavailability and the efficiency of the reduction-sensitive nanosystem as depleting endogenous antioxidants, such as GSH, makes cancer cells more chemosensitive. A new class of GSH-responsive CD nanosponges (GSH-NS) was then designed to preferentially release doxorubicin in cells with high GSH content. Doxorubicin-loaded GSH-NS inhibited clonogenic growth, cell viability, topoisomerase II activity and induced DNA damage with higher effectiveness than the free drug in various cancer cell lines. It is worth noting that GSHNS were able to reduce human prostatic tumour development more than the free drug, without evidence of significant organ toxicity in a xenograft model [24]. Doxorubicin-GSH-NS can affect cell proliferation at doses lower than the free-form drug, which allows effective drug doses and, therefore, systemic adverse effects to be reduced.

\section{Nanosystems that are responsive to external stimuli}

\subsection{Light responsive NPs}

Light-responsive nanosystems are a way to trigger drug release at a desired target using external light at appropriate wavelengths. However, the poor penetration depth of light into tissues currently limits its applications. Light-triggered release can be achieved by conjugating drugs to the nanosystems via photo-cleavable bonds or by developing photosensitive carriers that are able to provide on/off drug release via changes in their nanostructure under light exposure. For example, NIRtriggered release has been observed in poly(lactic-co-glycolic acid) matrix particles containing doxorubicin and covered with a gold over-layer [25]. Gold-containing DDSs have attracted a great deal of attention in recent years due to their enhanced and tunable optical properties, easy production and functionalization as well as good biocompatibility. Moreover, gold NPs set themselves apart from other nanoplatforms thanks to their unique localized surface plasmon resonance (SPR), which can be used in the multimodal treatment of cancer, an example of which is photothermal therapy [26]. Under NIR irradiation, the SPR of the gold NPs causes the local temperature to increase above body temperature by several degrees. For example, this feature is being used in AuroShells, which are gold nanoshells that are already in clinical trials for the treatment of solid tumours. After intravenous injection, these nanosystems are irradiated with a fibre-optic laser to provide high temperatures to the tumour area for the photothermal therapy of cancer [27]. Moreover, the surface of gold NPs is suitable for the conjugation of drugs, oligonucleotides and peptides making gold NPs appropriate platforms for DDS that can be activated by external stimuli. 


\subsection{Temperature -responsive and US responsive NPs and NBs}

Temperature is one of the most convenient and effective factors that can be used to control drug release. In pathophysiological conditions, such as tumours, tissue temperatures are higher than those in healthy tissues. This temperature difference allows functionalized nanosystems to be triggered and enhances drug release in tumours. Thermo-sensitive nanocarriers are usually designed to retain the drug at physiological temperature $\left(37^{\circ} \mathrm{C}\right)$, and rapidly release it when the temperature is higher than $40-45^{\circ} \mathrm{C}$. This is commonly the reason for NB release, but a number of different nanosystems have been designed with the aim of maintaining safety without losing sensitivity to slight temperature differences.

Tumour-specific drug accumulation can be achieved by combining hyperthermia and temperature-sensitive liposomes. ThermoDox, which is a temperature-sensitive doxorubicin liposome formulation, is probably the closest to clinical use at the moment. This nanosystem was designed to simultaneously achieve the passive targeting of doxorubicin towards tumour tissues and enhanced drug delivery in tumour microvasculature by applying an external source of heating, such as US. Dipalmitoyl phosphatidylcholine's lipid-crystallization melting temperature of $41.5^{\circ} \mathrm{C}$ means that doxorubicin is released from the nanosystem at this temperature. Moreover, radiofrequency ablation was also used to trigger drug release from ThermoDox. Liver-cancer targeted ThermoDox displayed an improved safety profile compared to free doxorubicin in a Phase I clinical trial. Although the life span after ThermoDox treatment failed to reach the 33\% threshold in Phase III clinical trials, the treatment strategy has a promising future as a stimuli-responsive DDS [19].

\subsection{US responsive NPS and NBs}

US has been extensively used in clinics for diagnosis and therapy because of its intrinsic tissue penetration and high safety; low-frequency US can penetrate several centimetres into the body with very low scattering [18].

US can affect tissues via a variety of mechanisms, thermal and non-thermal, and by tuning frequency, power intensity and exposure time. The heat generation produced by US is a well-known mechanism and is used in so-called high intensity focused ultrasound (HIFU) for the treatment of prostatic cancer [28], whereas the therapeutic uses of non-thermal US have been investigated less thoroughly. Besides the direct thermal effect, the effects of US on tissues include: a) alterations in biobarrier permeability (namely sonoporation), b) drug delivery and c) sonodynamic activity. The last of these effects has opened up new perspectives for cancer treatment, including sonodynamic therapy (SDT), in which a nontoxic molecule or system (chemical actuator, sonosensitizer) is activated by US (physical activator) and yields oxidative damage and consequent cancer cell death. SDT is thus achieved by an external physical stimulus that activates molecules or colloidal systems providing, in turn, a biological effect only when the two are combined together. Briefly, acoustic cavitation is defined as the formation or activity of gas- or vapour-filled cavities (bubbles) in a medium exposed to an US field. Specifically, bubbles in a stable cavitation state oscillate, which causes the surrounding liquid to stream, resulting in the mixing of the surrounding media, whereas gas bubbles in an inertial cavitation state grow to nearresonance size and expand to a maximum before collapsing violently. In this latter case, the extreme temperatures, up to $10,000 \mathrm{~K}$, and pressures, up to $81 \mathrm{MPa}$, that are produced in the surrounding microenvironment by the energy released during implosion are viewed as constituting a "sonochemical reactor" [29]. In anticancer sonodynamic activity, NPs may not only act as a sonosensitiser vehicle capable of improved and spatio-temporal controlled anticancer activity upon external US stimulus, but also as a sonosensitiser per se if appropriately designed [30].

In the field of US-responsive drug delivery systems, the use of NB in combination with US is also attractive for the targeted delivery of nucleic acids [31]. This could be achieved using various loading methods, such as the direct physical incorporation of DNA into the shell during fabrication, the use of cationic lipids or polymers in the shell to bind DNA by electrostatic interaction, and the covalent linking of DNA-NPs.

The authors of the present manuscript have exploited the capabilities of various nanosystems and used them as delivery systems for US-responsive chemical compounds (sonosensitisers), and as US-responsive systems themselves for the sonodynamic treatment of cancer. We demonstrated the significant anticancer activity of poly-methyl methacrylate core-shell NPs loaded with meso-tetrakis (4-sulfonatophenyl) porphyrin (TPPS-PMMANP) under US exposure at the target site in an in vitro neuroblastoma model [32]. These porphyrinloaded core-shell NPs were then engineered for use as in vivo sonosensitizing systems, radiotracers and magnetic resonance (MR) imaging agents, which may be suitable for the selective treatment of solid tumours and imaging analyses. Indeed, PMMANP were either loaded with TPPS for sonodynamic anticancer treatment, with ${ }^{64} \mathrm{Cu}$-TPPS for positron emission tomography biodistribution studies or with Mn(III)-TPPS for MR tumour accumulation evaluation. TPPSPMMANP demonstrated US responsiveness, as measured by MR analyses of pre- and post-treatment tumour volumes, in a syngeneic breast cancer model, proving that this multimodal system can efficiently induce selective and externally guided anticancer activity [33].

The properties of inorganic NPs, in this case gold NPs, have been investigated to harness their unique SPR phenomenon. Folate-PEG decorated gold NPs (FA-PEG-GNP) were tested as sonosensitizers for the treatment of cancer. Their US responsiveness in human cancer cell lines that expressed varying amounts of folate receptors was tested, and FA-PEG-GNP was found to selectively target folate-receptor overexpressing cancer cells providing a significant reduction in cell growth upon US exposure, along with impressive reactive oxygen species generation and an increase in necrotic cells [34]. The simultaneous exploitation of the gold NP targeting capacity and the sensitizing effect afforded by localized external stimuli make these nanosystems promising candidates for the site-specific treatment of cancer. This in vitro study can be considered proof of concept for gold NP use as nanosonosensitizers in the US-based treatment of cancer.

Formulations that are referred to as "NBs", prior to the application of external stimuli such as US, should be considered "nanodroplets" when the core is constituted of perfluoropentane, which is a perfluorocarbon that is found in the liquid state at room temperature (boiling point $29^{\circ} \mathrm{C}$ ). Release can be activated in the presence of US via the Acoustic Droplet Vaporization (ADV) mechanism [35].

The feasibility of combining NB with US as a topical treatment for skin disease has been investigated in the design of a therapeutic tool to topically treat hypoxia-associated dermal pathologies and promote the wound-healing process [36].

Dextran- and chitosan-shelled NBs loaded with decafluoropentane (called nanodroplets) or dodecafluoropentane (called NBs) have been developed as oxygen delivery systems 
thanks to the ability of perfluorocarbons to solubilize and store oxygen in the core and release it with prolonged kinetics [36-39]. Decafluoropentane systems have shown marked effectiveness, both in vitro and in vivo, in releasing oxygen to hypoxic environments, as demonstrated by complementary analysis that made use of oxymetry and photoacoustic imaging. Chitosan-shelled and oxygen-loaded nanodroplets were proposed $[36,40]$ as an innovative tool for the adjuvant treatment of infected chronic wounds by exploiting chitosan's antimicrobial properties.

Oxygen-loaded nanodroplets have shown significant cytostatic activity against methicillin-resistant Staphylococcus aureus (MRSA) and Candida Albicans, and no toxicity in human keratinocytes (HaCaT cells). Moreover, complementary US treatment promoted oxygen transdermal delivery from the nanodroplets to hypoxic tissues. Much research has been devoted in recent years to the study of NB formulations to carry oxygen as exogenous oxygen is difficult to deliver into tumours that are distant from blood vessels. The high oxygen solubility of bubbles is beneficial for hypoxic tissue oxygenation.

New vancomycin-loaded dextran sulfate-shelled NBs have been designed [41] for local drug delivery for the treatment of cutaneous infectious disease. The combination of vancomycinloaded NB and US enhanced the drug's penetration through the skin by sonophoresis and triggered local drug release at the site of infection.

Diethylaminoethyl-dextran (DEAE)-shelled NBs have been found to incorporate and protect DNA from the action of proteases and transfect plasmid DNA across the cell membrane without any resulting cytotoxic effects [42]. Another NB formulation, consisting of a chitosan-based shell, has also been designed for DNA delivery. DNA-loaded chitosan NBs with a mean diameter of less than $300 \mathrm{~nm}$ and a good DNA payload were obtained [43]. In vitro transfection experiments were performed by exposing adherent COS7 cells to US (2.5 $\mathrm{MHz}$ ) in the presence of varying concentrations of plasmid DNA-loaded NBs. NBs failed to trigger transfection in the absence of US at all concentrations tested. By contrast, 30 seconds of US promoted a moderate degree of transfection. Cell viability experiments demonstrated that neither US nor NB affected cell viability under these experimental conditions.

Continuous efforts in the field of cancer immunotherapy in recent years have led to the development of several vaccination strategies that are based on tumour-associated-antigens, such as the HER2 oncogene.

Cancer vaccination offers distinct advantages over standard therapies. These advantages include higher specificity, lower toxicity and reduced long-term effects, which are all due to immunologic memory. Nanotechnology has great potential to make immune therapy more efficient. Indeed, in order to correctly expand the immune response against tumours, a vaccine needs to effectively reach the dendritic cells, which play a critical role in inducing a proper immune activation.

A novel immunotherapeutic tool, which is based on chitosanshelled NBs loaded with a DNA vaccine and functionalized with anti-CD11c antibodies to target DCs, has recently been developed for the treatment of HER2+ breast cancer [44]. The intradermal injection of pHER2-loaded CD11c-NBs led to the migration of dermal DCs to draining lymph nodes and the delayed growth of HER2+ tumours, thus promoted cellular and humoral immune responses were observed in the mouse model.

Various NB formulations have been investigated as theranostic platforms with the intention of exploiting their echogenic properties. In fact, polymer-shelled NBs have been widely proposed as multifunctional agents with the aim of providing cancer cell targeting, US imaging and US-triggered cancer therapy.

The authors of the present review have tuned a chitosanbased NB formulation to act as a theranostic system that can provide the double imaging detection of NBs [45]. The formulation was designed for the co-delivery of prednisolone phosphate, located at the interface with the perfluoropentane core, and a negatively charged GD-DOTP complex, which was electrostatically bound to the cationic chitosan NB shell. The NBs were echogenic, meaning that it may be possible to visualize them by means of real-time echography imaging, while the ability to generate positive MRI contrast was demonstrated.

Extracorporeal Shock Waves (ESWs) have also been studied as another physical external stimulus with which to trigger drug release from NBs, besides US. ESWs are shortduration $(<10 \mu \mathrm{s})$ focused acoustic waves that are widely used in urology for lithotripsy and for the treatment of several musculoskeletal diseases. The effectiveness of using drugloaded NBs together with Extracorporeal Shock Waves (ESW) was thoroughly investigated. Interestingly, the effects of combining chemotherapeutic drug-loaded NBs and ESWs have recently been demonstrated in two different types of aggressive cancers, anaplastic thyroid cancer (ATC) and castration resistant prostate cancer (CRPC) [46-49]. Moreover, Marano et al. have reported that combined treatment with either paclitaxel- or docetaxel-loaded NBs and ESW enhanced the cytotoxicity of both the drugs in two different cell lines (PC3 and DU145) of CRPC, resulting in a paclitaxel Gl50 reduction of about $55 \%$ and in a docetaxel Gl50 reduction of about $45 \%$ (Fig. 2) [48].

\subsection{Magnetic responsive NPs}

Magnetic stimuli may provide a non-invasive approach to the temporal and spatial control of carrier targeting and drug release under the programmable exposure of an external magnetic field. The most commonly-used core/shell magnetic NPs (MNP) exhibit a variety of unique magnetic properties. The large surface-to-volume ratio of MNPs provides abundant active sites for biomolecule conjugation and thus facilitates their precise design and engineering, which should ensure that their intended smart capabilities, such as long-lasting circulation in the blood stream, target specificity to lesion tissues, and therapeutic delivery, operate efficiently under the action of a localized external magnetic field. Temperature increases can be obtained using a variety of energy sources, with the most commonly used being electromagnetic (EM) energy. Hyperthermia $(\mathrm{HT})$ is typically performed at high frequencies (13 MHz to $430 \mathrm{MHz}$ according to tumour depth) with phasedarray antennas being placed outside the body, while MWs (915 MHz or $2.45 \mathrm{GHz}$ ) are applied in thermal ablation (MTA) through interstitial antennas placed in the tumour centre. Both HT and MTA have proven their safety and efficacy in several clinical trials [50]. However, both techniques suffer from poor reproducibility and difficulties in controlling the temperature distribution inside the tumour over the various clinical conditions. Research is thus currently being devoted to the improvement of heating uniformity and target specificity, while aiming to minimise invasiveness. A promising route to this aim can be found in MNP-mediated thermotherapies, which are used as sources of local heating after their injection into the tissue and successive exposure to external magnetic fields. The main limitation of magnetic thermotherapy is the poor heating efficiency of most magnetic nanomaterials, so that therapeutic effects are only observed when large amounts of MNP are 
A

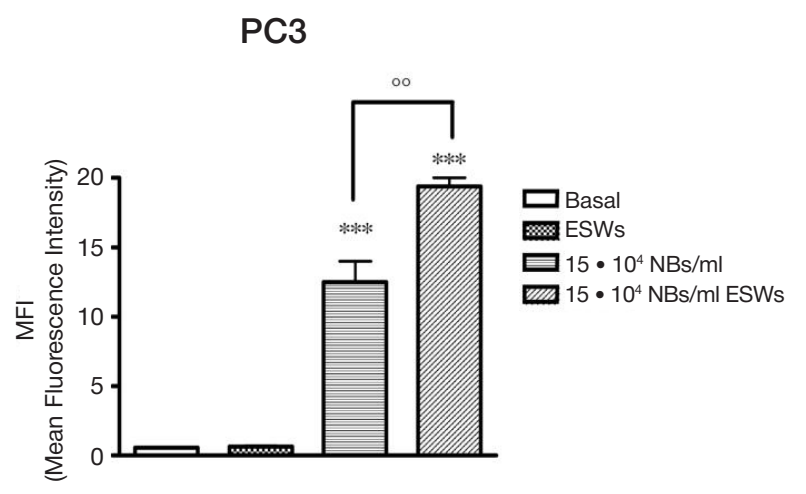

B

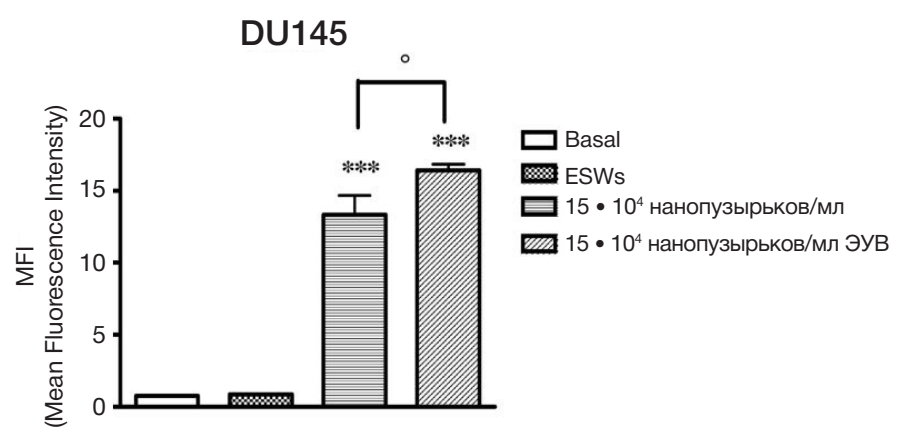

C

D

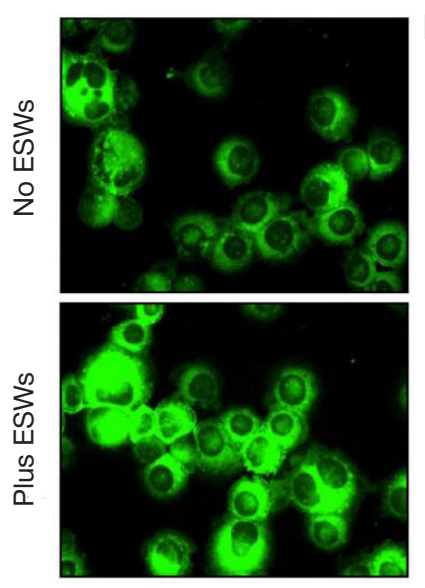

E
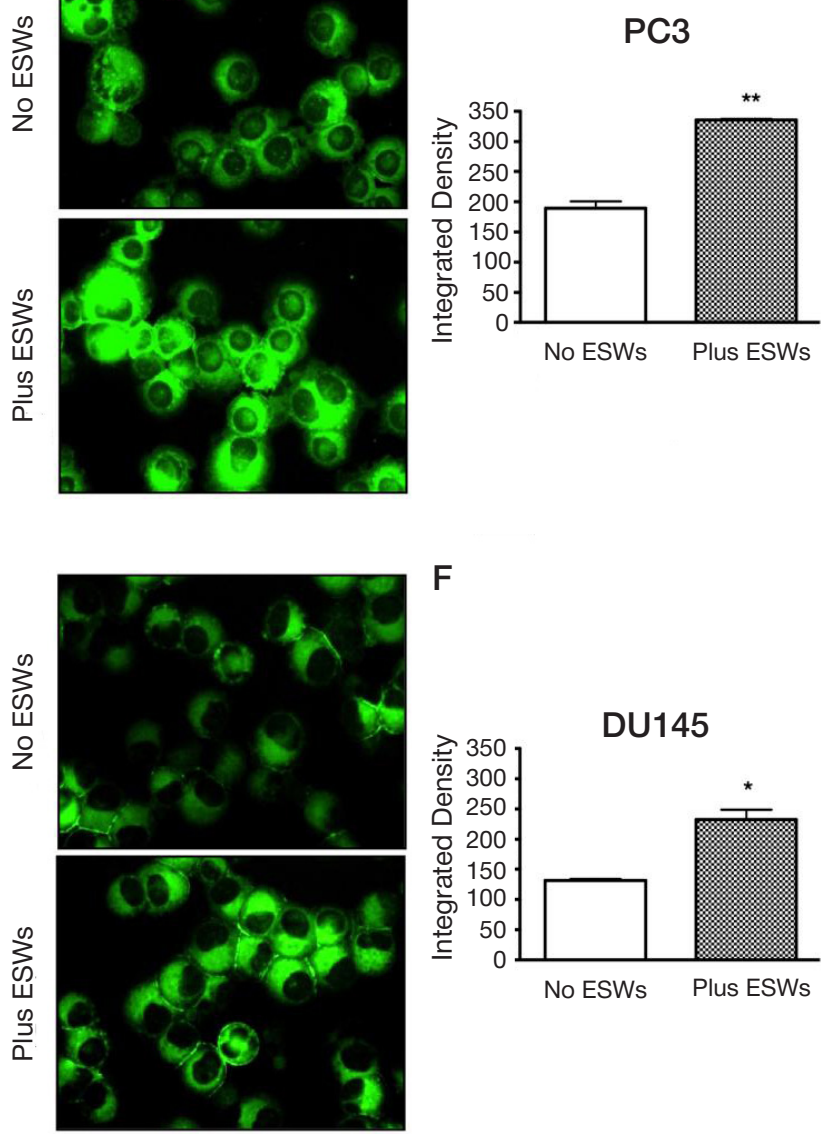

$\mathrm{F}$

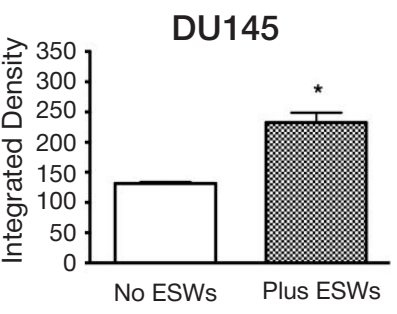

Fig. 2. Nanobubble entrance. Cytofluorimetric analysis of PC3 (A) and DU145 (B) cells treated for 24 hours with 6-coumarin-labelled glycol chitosan NBs (15 • 104 NBs/ml), either in the absence and in the presence of ESWs, expressed as Mean Fluorescence Intensity (MFI). Significance vs untreated cells (Basal): $p<0.001$ (***); significance vs ESWs: $p<0.05\left({ }^{\circ}\right) ; p<0.01\left(^{\circ}\right)$. Photos by fluorescence microscope of PC3 (C) and DU145 (D) cells treated with 6-coumarin-labelled glycol chitosan NBs at $15 \bullet 10^{4} \mathrm{NBs} / \mathrm{ml}$, either in the absence and in the presence of ESWs. Pictures were taken at $\times 200$ final magnification (scale bar: $\left.100 \mu \mathrm{m}\right)$. The images are representative of three independent experiments; for each experiment, 10 fields were quantified. Image-based quantification of 6-coumarin-labelled glycol chitosan NBs in PC3 (E) and DU145 (F) cells. Significance vs no ESWs: $p<0.05\left(^{\star}\right) ; p<0.01{ }^{* \star}{ }^{*}$. [ref 48]

injected into the tumour. Significant work is accordingly being performed on the optimization of heating efficiency and biocompatibility by tuning MNP size and physical properties, as well as considering several different coating materials. Magnetic nanodisks (MND) and nanorings have recently emerged as a valid alternative to MNPs, as they are characterized by negligible remnant magnetization and the consequent advantageous reduction of the long-range magnetostatic forces responsible for particle agglomeration. Preliminary studies demonstrated the potential of these nanostructures as effective nanomediators for cancer thermotherapy as they show improved HT properties with respect to isotropic MNPs. Magnetic Ni80Fe20 NPs with a disc shape have been obtained by nanolithography and were directly coated with a gold layer [51]. Functionalization of the gold surface of coated MNDs was performed with a cysteine-fluorescein isothiocyanate (FITC) derivative, by the authors of the present manuscript, in order to induce random fluorescence for use as a means to evaluate intracellular uptake. The magnetization process of all the MNDs was characterized by the presence of a vortex which pointing to a possible exploitation in drug delivery process and also in magnetic hyperthermia. It is worth noting that cytotoxicity tests confirmed that gold-coated MNDs displayed higher biocompatibility than the bare nanodisks despite not being completely coated. The intracellular uptake of the MNDs was confirmed by cytofluorimetric analysis using the FITC conjugate on the surface of the gold-coated MNDs [52].

\section{CONCLUSIONS}

Smart DDSs have proven themselves to be highly efficient in biomedical applications. However, their potential druggability still requires extensive evaluation before clinical use is feasible. Indeed, there are a number of stimuli-responsive nanosystems are currently undergoing clinical evaluation, but only a few have been approved for clinical use, such as NanoTherms ${ }^{\oplus}$, and most of them are commercialized for research use only [18]. Future work on smart DDSs should therefore be focused on more feasible and homogeneous preparation methods and on clinical translation to ensure that more stimulus-sensitive nanomedicines can see use in clinics. Indeed, improving the preclinical research of advanced DDSs to make them more reproducible and then translate that to success into clinical trials will be an enormous challenge for researchers. 
1. Portehault D, Delacroix S, Gouget G, Grosjean R, Chan-Chang T-H-C Beyond the Compositional Threshold of Nanoparticle-Based Materials. Accounts of Chemical Research. 2018; 51 (4): 930-9.

2. Cravotto G, Boffa L. Preparation of nanomaterials under combined ultrasound/microwave irradiation. Pan Stanford Publishing Pte. Ltd.: 2014; p. 203-26.

3. Martina K, Tagliapietra S, Barge A, Cravotto G. Combined Microwaves/Ultrasound, a Hybrid Technology. Top Curr Chem. 2016; 374 (6): 1-27.

4. Davis ME, Brewster ME. Cyclodextrin-based pharmaceutics: past, present and future. Nat Rev Drug Discov. 2004; (3): 1023-35.

5. Barge A, Caporaso M, Cravotto G, Martina K, Tosco P, Aime S et al. Design and Synthesis of a $\gamma 1 \beta 8$-Cyclodextrin Oligomer: A New Platform with Potential Application as a Dendrimeric Multicarrier Chem Eur J. 2013; 19 (36): 12086-92.

6. Martina K, Baricco F, Berlier G, Caporaso M, Cravotto G Efficient Green Protocols for Preparation of Highly Functionalized ß-Cyclodextrin-Grafted Silica. ACS Sustainable Chem Eng. 2014; 2 (11): 2595-603.

7. Huq R, Mercier L, Kooyman PJ. Incorporation of Cyclodextrin into Mesostructured Silica. Chem Mater. 2001; 13 (12): 4512-9.

8. Lee J-H, Kang S, Ahn M, Jang H, Min D-H. Development of dualpore coexisting branched silica nanoparticles for efficient genechemo cancer therapy. Small. 2018; 14 (7): 1702564.

9. Calcio Gaudino E, Tagliapietra S, Martina K, et al. Novel SWCNT platform bearing DOTA and $\beta$-cyclodextrin units. "One shot" multidecoration under microwave irradiation. Org Biomol Chem. 2014; (12): 4708-15.

10. Bosca F, Orio L, Tagliapietra S, Corazzari I, TurciF, Martina K, Pastero L, Cravotto G et al. Microwave-Assisted Synthesis and Physicochemical Characterization of TetrafuranylporphyrinGrafted Reduced-Graphene Oxide. Chem Eur J. 2016; (22): 1608-13.

11. Duan S, Li J, Zhao N, Xu F-J. Multifunctional hybrids with versatile types of nanoparticles via self-assembly for complementary tumor therapy. Nanoscale. 2018; (10): 7649-57.

12. Bolden NW, Rangari VK, Jeelani S, Boyoglu S, Singh SR Synthesis and evaluation of magnetic nanoparticles for biomedica applications. J Nanopart. 2013: 1-9; DOI:10.1155/2013/370812.

13. Güvener N, Appold L, de Lorenzi F, Golombek SK, Rizzo LY Lammers T, Kiessling F. Recent advances in ultrasoundbased diagnosis and therapy with micro-and nanometer-sized formulations. Methods. 2017; (130): 4-13.

14. Cavalli R, Soster M, Argenziano M. Nanobubbles: a promising efficient tool for therapeutic delivery. Ther Deliv. 2016; 7 (2): 117-38.

15. Delalande A, Postema M, Mignet N, Midoux P, Pichon C. Ultrasound and microbubble-assisted gene delivery: recent advances and ongoing challenges. Ther Deliv. 2012; 3 (10): 1199-215

16. Cavalli R, Bisazza A, Giustetto P, Civra A, Lembo D, Trotta G et al. Preparation and characterization of dextran nanobubbles for oxygen delivery. Int J Pharm. 2009; 381 (2): 160-5.

17. Malam Y, Loizidou M, Seifalian AM. Liposomes and nanoparticles: nanosized vehicles for drug delivery in cancer. Trends Pharmacol Sci. 2009 Nov; 30 (11): 592-9.

18. Alvarez-Lorenzo C1, Concheiro A. Smart drug delivery systems: from fundamentals to the clinic. Chem Commun. 2014; 50 (58): 7743-65.

19. Liu D, Yang F, Xiong F, Gu N. The Smart Drug Delivery System and Its Clinical Potential. Theranostics. 2016 Jun 7; 6 (9): 1306-23.

20. Sharifi S, Behzadi S, Laurent S, Forrest ML, Stroeve P, Mahmoudi M. Toxicity of nanomaterials. Chem Soc Rev. 2012 Mar 21; 41 (6) 2323-43.

21. Caldera F, Argenziano M, Trotta F, Dianzani C, Gigliotti L, Tannous M et al. Cyclic nigerosyl-1,6-nigerose-based nanosponges: An innovative $\mathrm{pH}$ and time-controlled nanocarrier for improving cancer treatment. Carbohydr Polym. 2018; (194): 111-21.

22. Chen X, Yao X, Wang C, Chen L, Chen X. Mesoporous silica nanoparticles capped with fluorescence-conjugated cyclodextrin for $\mathrm{pH}$-activated controlled drug delivery and imaging. Microporous Mesoporous Mater. 2015; (217): 46-53.
23. Torchilin VP. Multifunctional, stimuli-sensitive nanoparticulate systems for drug delivery. Nat Rev Drug Discov. 2014 Nov; 13 (11): 813-27.

24. Daga M, Ullio C, Argenziano M, Dianzani C, Cavalli R, Trotta F et al. GSH-targeted nanosponges increase doxorubicin-induced toxicity "in vitro" and "in vivo" in cancer cells with high antioxidant defenses. Free Radic Biol Med. 2016; (97): 24-37.

25. Yang J, Lee J, Kang J, Oh SJ, Ko HJ, Son JH et al. Smart drug-loaded polymer gold nanoshells for systemic and localized therapy of human epithelial cancer. Adv Mater. 2009 Nov 20; 21 (43): 4339-42.

26. Shukla R, Bansal V, Chaudhary M, Basu A, Bhonde RR, Sastry M. Biocompatibility of gold nanoparticles and their endocytotic fate inside the cellular compartment: a microscopic overview. Langmuir. 2005 Nov 8; 21 (23): 10644-54.

27. Schwartz JA, Shetty AM, Price RE, Stafford RJ, Wang JC, Uthamanthil RK et al. Feasibility study of particle-assisted laser ablation of brain tumors in orthotopic canine model. Cancer Res. 2009 Feb 15; 69 (4): 1659-67.

28. Maloney E, Hwang $\mathrm{JH}$. Emerging HIFU applications in cancer therapy. Int J Hyperthermia. 2015; 31 (3): 302-9.

29. Giuntini F, Foglietta F, Marucco AM, Troia A, Dezhkunov NV, Pozzoli A et al. Insight into ultrasound-mediated reactive oxygen species generation by various metal-porphyrin complexes. Free Radic Biol Med. 2018; (121): 190-201.

30. Serpe L, Foglietta F, Canaparo R. Nanosonotechnology: The next challenge in cancer sonodynamic therapy. Nanotechnology Reviews. 2012; 1 (2): 173-82.

31. Cavalli R, Bisazza A, Lembo D. Micro-and nanobubbles: a versatile non-viral platform for gene delivery. Int J Pharm. 2013; 456 (2): 437-45.

32. Canaparo R, Varchi G, Ballestri M, Foglietta F, Sotgiu G, Guerrini A et al. Polymeric nanoparticles enhance the sonodynamic activity of meso-tetrakis (4-sulfonatophenyl) porphyrin in an in vitro neuroblastoma model. Int J Nanomedicine. 2013; (8): 4247-63.

33. Varchi G, Foglietta F, Canaparo R, Ballestri M, Arena F, Sotgiu G et al. Engineered porphyrin loaded core-shell nanoparticles for selective sonodynamic anticancer treatment. Nanomedicine 2015; 10 (23): 3483-94.

34. Brazzale C, Canaparo R, Racca L, Foglietta F, Durando G, Fantozzi $R$ et al. Enhanced selective sonosensitizing efficacy of ultrasound-based anticancer treatment by targeted gold nanoparticles. Nanomedicine. 2016; 11 (23): 3053-70.

35. Kripfgans OD, Fowlkes JB, Miller DL Eldevik OP, Carson PL. Acoustic droplet vaporization for therapeutic and diagnostic applications. Ultrasound Med Biol. 2000; 6 (7): 1177-89.

36. Prato M, Magnetto C, Jose J, Khadjavi A, Cavallo F, Quaglino E et al. 2H, 3H-decafluoropentane-based nanodroplets: new perspectives for oxygen delivery to hypoxic cutaneous tissues. PLoS One. 2015; 10 (3): e0119769.

37. Basilico N, Magnetto C, D'Alessandro S, Panariti A, Rivolta I, Genova $\mathrm{T}$ et al. Dextran-shelled oxygen-loaded nanodroplets reestablish a normoxia-like pro-angiogenic phenotype and behavior in hypoxic human dermal microvascular endothelium, Toxicol Appl Pharmacol. 2015; 288 (3): 330-8.

38. Cavalli R, Bisazza A, Rolfo A, Balbis S, Madonnaripa D, Caniggia I et al. Ultrasound-mediated oxygen delivery from chitosan nanobubbles. Int J Pharm. 2009; 378 (1-2): 215-7.

39. Khadjavi A, Magnetto C, Panariti A, Argenziano M, Gulino GR, Rivolta I et al. Chitosan-shelled oxygen-loaded nanodroplets abrogate hypoxia dysregulation of human keratinocyte gelatinases and inhibitors: new insights for chronic wound healing. Toxicol Appl Pharmacol. 2015; 286 (3): 198-206.

40. Banche G, Prato M, Magnetto C, Allizond V, Giribaldi G, Argenziano M et al. Antimicrobial chitosan nanodroplets: new insights for ultrasound-mediated adjuvant treatment of skin infection. Future Microbiol. 2015; 10 (6): 929-39.

41. Argenziano M, Banche G, Luganini A, Finesso N, Allizond V, Gulino GR et al. Vancomycin-loaded nanobubbles: A new platform for controlled antibiotic delivery against methicillinresistant Staphylococcus aureus infections. Int J Pharm. 2017; 
523 (1): 176-88.

42. Bisazza A, Civra A, Donalisio M, Lembo D, Cavalli R. The in vitro characterization of dextran-based nanobubbles as possible DNA transfection agents. Soft Matter. 2011; 7 (22): 10590-3.

43. Cavalli R, Bisazza A, Trotta M, Argenziano M, Civra A, Donalisio M et al. New chitosan nanobubbles for ultrasound-mediated gene delivery: preparation and in vitro characterization. Int $J$ Nanomedicine. 2012; (7): 3309-18.

44. Cavalli R, Occhipinti S, Argenziano M, Bessone F, Guiot C, Giovarelli M. Nanobubble technology-based HER2 immunotherapy through dendritic cells targeting. Presented at "CRS Annual Meeting \& Exposition", July 16-19 2017; Boston, Massachusetts, USA.

45. Cavalli R, Argenziano M, Vigna E, Giustetto P, Torres E, Aime S et al. Preparation and in vitro characterization of chitosan nanobubbles as theranostic agents. Colloids Surf B Biointerfaces. 2015; (129): 39-46.

46. Marano $F$, Argenziano $M$, Frairia $R$, Adamini $A$, Bosco $O$, Rinella $L$ et al. Doxorubicin-loaded nanobubbles combined with extracorporeal shock waves: basis for a new drug delivery tool in anaplastic thyroid cancer. Thyroid. 2016; 26 (5): 705-16.

47. Marano F, Frairia R, Rinella L, Argenziano M, Bussolati B, Grange C et al. Combining doxorubicin-nanobubbles and shockwaves for anaplastic thyroid cancer treatment: preclinical study in a xenograft mouse model. Endocr Relat Cancer. 2017; 24 (6): 275-86.

48. Marano F, Rinella L, Argenziano M, Cavalli R, Sassi F, D'Amelio P et al. Targeting Taxanes to Castration-Resistant Prostate Cancer Cells by Nanobubbles and Extracorporeal Shock Waves. PloS One. 2016; 11 (12): e0168553.

49. Roberta C, Francesca M, Monica A, Alessandra V, Roberto F, Maria Graziella C. Combining Drug-Loaded Nanobubbles and Extracorporeal Shock Waves for Difficult-to-Treat Cancers. Current Drug Delivery. 2017; (14): 1-3.

50. Glazer ES, Curley SA. The ongoing history of thermal therapy for cancer. Surg Oncol Clin N Am. 2011; 20 (2): 229-35.

51. Kosiorek A, Kandulski W, Glaczynska H, Giersig M. Fabrication of nanoscale rings, dots, and rods by combining shadow nanosphere lithography and annealed polystyrene nanosphere masks. Small. 2005; (1): 439-44.

52. Barrera G, Serpe L, Celegato F, Coïsson M, Martina K, Canaparo R et al. Surface modification and cellular uptake evaluation of Aucoated Ni80Fe20 nanodiscs for biomedical applications. Interface Focus. 2016; 6 (6). DOI: 10.1098/rsfs.2016.0052.

\section{Литература}

1. Portehault D, Delacroix S, Gouget G, Grosjean R, Chan-Chang T-H-C. Beyond the Compositional Threshold of Nanoparticle-Based Materials. Accounts of Chemical Research. 2018; 51 (4): 930-9.

2. Cravotto G, Boffa L. Preparation of nanomaterials under combined ultrasound/microwave irradiation. Pan Stanford Publishing Pte. Ltd.: 2014; p. 203-26.

3. Martina K, Tagliapietra S, Barge A, Cravotto G. Combined Microwaves/Ultrasound, a Hybrid Technology. Top Curr Chem. 2016; 374 (6): 1-27.

4. Davis ME, Brewster ME. Cyclodextrin-based pharmaceutics: past, present and future. Nat Rev Drug Discov. 2004; (3): 1023-35.

5. Barge A, Caporaso M, Cravotto G, Martina K, Tosco P, Aime S et al. Design and Synthesis of a $\gamma 1 \beta 8$-Cyclodextrin Oligomer: A New Platform with Potential Application as a Dendrimeric Multicarrier. Chem Eur J. 2013; 19 (36): 12086-92.

6. Martina K, Baricco F, Berlier G, Caporaso M, Cravotto G. Efficient Green Protocols for Preparation of Highly Functionalized $\beta$-Cyclodextrin-Grafted Silica. ACS Sustainable Chem Eng. 2014; 2 (11): 2595-603.

7. Huq R, Mercier L, Kooyman PJ. Incorporation of Cyclodextrin into Mesostructured Silica. Chem Mater. 2001; 13 (12): 4512-9.

8. Lee J-H, Kang S, Ahn M, Jang H, Min D-H. Development of dualpore coexisting branched silica nanoparticles for efficient genechemo cancer therapy. Small. 2018; 14 (7): 1702564.

9. Calcio Gaudino E, Tagliapietra S, Martina K, et al. Novel SWCNT platform bearing DOTA and $\beta$-cyclodextrin units. "One shot" multidecoration under microwave irradiation. Org Biomol Chem. 2014; (12): 4708-15.

10. Bosca F, Orio L, Tagliapietra S, Corazzari I, TurciF, Martina K, Pastero L, Cravotto G et al. Microwave-Assisted Synthesis and Physicochemical Characterization of TetrafuranylporphyrinGrafted Reduced-Graphene Oxide. Chem Eur J. 2016; (22): 1608-13.

11. Duan S, Li J, Zhao N, Xu F-J. Multifunctional hybrids with versatile types of nanoparticles via self-assembly for complementary tumor therapy. Nanoscale. 2018; (10): 7649-57.

12. Bolden NW, Rangari VK, Jeelani S, Boyoglu S, Singh SR. Synthesis and evaluation of magnetic nanoparticles for biomedical applications. J Nanopart. 2013: 1-9; DOI:10.1155/2013/370812.

13. Güvener N, Appold L, de Lorenzi F, Golombek SK, Rizzo LY, Lammers T, Kiessling F. Recent advances in ultrasoundbased diagnosis and therapy with micro-and nanometer-sized formulations. Methods. 2017; (130): 4-13.

14. Cavalli R, Soster M, Argenziano M. Nanobubbles: a promising efficient tool for therapeutic delivery. Ther Deliv. 2016; 7 (2): 117-38.

15. Delalande A, Postema M, Mignet N, Midoux P, Pichon C.

Ultrasound and microbubble-assisted gene delivery: recent advances and ongoing challenges. Ther Deliv. 2012; 3 (10): 1199-215.

16. Cavalli R, Bisazza A, Giustetto P, Civra A, Lembo D, Trotta G et al. Preparation and characterization of dextran nanobubbles for oxygen delivery. Int J Pharm. 2009; 381 (2): 160-5.

17. Malam Y, Loizidou M, Seifalian AM. Liposomes and nanoparticles: nanosized vehicles for drug delivery in cancer. Trends Pharmacol Sci. 2009 Nov; 30 (11): 592-9.

18. Alvarez-Lorenzo C1, Concheiro A. Smart drug delivery systems: from fundamentals to the clinic. Chem Commun. 2014; 50 (58): 7743-65.

19. Liu D, Yang F, Xiong F, Gu N. The Smart Drug Delivery System and Its Clinical Potential. Theranostics. 2016 Jun 7; 6 (9): 1306-23.

20. Sharifi S, Behzadi S, Laurent S, Forrest ML, Stroeve P, Mahmoudi M. Toxicity of nanomaterials. Chem Soc Rev. 2012 Mar 21; 41 (6): 2323-43.

21. Caldera F, Argenziano M, Trotta F, Dianzani C, Gigliotti L, Tannous M et al. Cyclic nigerosyl-1,6-nigerose-based nanosponges: An innovative $\mathrm{pH}$ and time-controlled nanocarrier for improving cancer treatment. Carbohydr Polym. 2018; (194): 111-21.

22. Chen X, Yao X, Wang $C$, Chen L, Chen X. Mesoporous silica nanoparticles capped with fluorescence-conjugated cyclodextrin for $\mathrm{pH}$-activated controlled drug delivery and imaging. Microporous Mesoporous Mater. 2015; (217): 46-53.

23. Torchilin VP. Multifunctional, stimuli-sensitive nanoparticulate systems for drug delivery. Nat Rev Drug Discov. 2014 Nov; 13 (11): 813-27.

24. Daga M, Ullio C, Argenziano M, Dianzani C, Cavalli R, Trotta F et al. GSH-targeted nanosponges increase doxorubicin-induced toxicity "in vitro" and "in vivo" in cancer cells with high antioxidant defenses. Free Radic Biol Med. 2016; (97): 24-37.

25. Yang J, Lee J, Kang J, Oh SJ, Ko HJ, Son JH et al. Smart drug-loaded polymer gold nanoshells for systemic and localized therapy of human epithelial cancer. Adv Mater. 2009 Nov 20; 21 (43): 4339-42.

26. Shukla R, Bansal V, Chaudhary M, Basu A, Bhonde RR, Sastry M. Biocompatibility of gold nanoparticles and their endocytotic fate inside the cellular compartment: a microscopic overview. Langmuir. 2005 Nov 8; 21 (23): 10644-54.

27. Schwartz JA, Shetty AM, Price RE, Stafford RJ, Wang JC, Uthamanthil RK et al. Feasibility study of particle-assisted laser ablation of brain tumors in orthotopic canine model. Cancer Res. 2009 Feb 15; 69 (4): 1659-67.

28. Maloney E, Hwang JH. Emerging HIFU applications in cancer therapy. Int J Hyperthermia. 2015; 31 (3): 302-9. 
29. Giuntini F, Foglietta F, Marucco AM, Troia A, Dezhkunov NV, Pozzoli A et al. Insight into ultrasound-mediated reactive oxygen species generation by various metal-porphyrin complexes. Free Radic Biol Med. 2018; (121): 190-201.

30. Serpe L, Foglietta F, Canaparo R. Nanosonotechnology: The next challenge in cancer sonodynamic therapy. Nanotechnology Reviews. 2012; 1 (2): 173-82.

31. Cavalli R, Bisazza A, Lembo D. Micro-and nanobubbles: a versatile non-viral platform for gene delivery. Int J Pharm. 2013; 456 (2): 437-45.

32. Canaparo R, Varchi G, Ballestri M, Foglietta F, Sotgiu G, Guerrini A et al. Polymeric nanoparticles enhance the sonodynamic activity of meso-tetrakis (4-sulfonatophenyl) porphyrin in an in vitro neuroblastoma model. Int J Nanomedicine. 2013; (8): 4247-63.

33. Varchi G, Foglietta F, Canaparo R, Ballestri M, Arena F, Sotgiu G et al. Engineered porphyrin loaded core-shell nanoparticles for selective sonodynamic anticancer treatment. Nanomedicine 2015; 10 (23): 3483-94.

34. Brazzale C, Canaparo R, Racca L, Foglietta F, Durando G, Fantozzi $R$ et al. Enhanced selective sonosensitizing efficacy of ultrasound-based anticancer treatment by targeted gold nanoparticles. Nanomedicine. 2016; 11 (23): 3053-70.

35. Kripfgans OD, Fowlkes JB, Miller DL Eldevik OP, Carson PL. Acoustic droplet vaporization for therapeutic and diagnostic applications. Ultrasound Med Biol. 2000; 6 (7): 1177-89.

36. Prato M, Magnetto C, Jose J, Khadjavi A, Cavallo F, Quaglino E et al. $2 \mathrm{H}, 3 \mathrm{H}$-decafluoropentane-based nanodroplets: new perspectives for oxygen delivery to hypoxic cutaneous tissues. PLoS One. 2015; 10 (3): e0119769.

37. Basilico N, Magnetto C, D'Alessandro S, Panariti A, Rivolta I, Genova $\mathrm{T}$ et al. Dextran-shelled oxygen-loaded nanodroplets reestablish a normoxia-like pro-angiogenic phenotype and behavior in hypoxic human dermal microvascular endothelium, Toxicol Appl Pharmacol. 2015; 288 (3): 330-8.

38. Cavalli R, Bisazza A, Rolfo A, Balbis S, Madonnaripa D, Caniggia I et al. Ultrasound-mediated oxygen delivery from chitosan nanobubbles. Int J Pharm. 2009; 378 (1-2): 215-7.

39. Khadjavi A, Magnetto C, Panariti A, Argenziano M, Gulino GR Rivolta I et al. Chitosan-shelled oxygen-loaded nanodroplets abrogate hypoxia dysregulation of human keratinocyte gelatinases and inhibitors: new insights for chronic wound healing. Toxicol Appl Pharmacol. 2015; 286 (3): 198-206.

40. Banche G, Prato M, Magnetto C, Allizond V, Giribaldi G, Argenziano M et al. Antimicrobial chitosan nanodroplets: new insights for ultrasound-mediated adjuvant treatment of skin infection. Future Microbiol. 2015; 10 (6): 929-39.
41. Argenziano M, Banche G, Luganini A, Finesso N, Allizond V, Gulino GR et al. Vancomycin-loaded nanobubbles: A new platform for controlled antibiotic delivery against methicillinresistant Staphylococcus aureus infections. Int J Pharm. 2017; 523 (1): 176-88.

42. Bisazza A, Civra A, Donalisio M, Lembo D, Cavalli R. The in vitro characterization of dextran-based nanobubbles as possible DNA transfection agents. Soft Matter. 2011; 7 (22): 10590-3.

43. Cavalli R, Bisazza A, Trotta M, Argenziano M, Civra A, Donalisio M et al. New chitosan nanobubbles for ultrasound-mediated gene delivery: preparation and in vitro characterization. Int $\mathrm{J}$ Nanomedicine. 2012; (7): 3309-18.

44. Cavalli R, Occhipinti S, Argenziano M, Bessone F, Guiot C, Giovarelli M. Nanobubble technology-based HER2 immunotherapy through dendritic cells targeting. Presented at "CRS Annual Meeting \& Exposition", July 16-19 2017; Boston, Massachusetts, USA.

45. Cavalli R, Argenziano M, Vigna E, Giustetto P, Torres E, Aime S et al. Preparation and in vitro characterization of chitosan nanobubbles as theranostic agents. Colloids Surf B Biointerfaces. 2015; (129): 39-46.

46. Marano F, Argenziano $M$, Frairia $R$, Adamini A, Bosco $O$, Rinella $L$ et al. Doxorubicin-loaded nanobubbles combined with extracorporeal shock waves: basis for a new drug delivery tool in anaplastic thyroid cancer. Thyroid. 2016; 26 (5): 705-16.

47. Marano F, Frairia R, Rinella L, Argenziano M, Bussolati B, Grange C et al. Combining doxorubicin-nanobubbles and shockwaves for anaplastic thyroid cancer treatment: preclinical study in a xenograft mouse model. Endocr Relat Cancer. 2017; 24 (6): 275-86.

48. Marano F, Rinella L, Argenziano M, Cavalli R, Sassi F, D'Amelio P et al. Targeting Taxanes to Castration-Resistant Prostate Cancer Cells by Nanobubbles and Extracorporeal Shock Waves. PloS One. 2016; 11 (12): e0168553.

49. Roberta C, Francesca M, Monica A, Alessandra V, Roberto F, Maria Graziella C. Combining Drug-Loaded Nanobubbles and Extracorporeal Shock Waves for Difficult-to-Treat Cancers. Current Drug Delivery. 2017; (14): 1-3.

50. Glazer ES, Curley SA. The ongoing history of thermal therapy for cancer. Surg Oncol Clin N Am. 2011; 20 (2): 229-35.

51. Kosiorek A, Kandulski W, Glaczynska H, Giersig M. Fabrication of nanoscale rings, dots, and rods by combining shadow nanosphere lithography and annealed polystyrene nanosphere masks. Small. 2005; (1): 439-44.

52. Barrera G, Serpe L, Celegato F, Coïsson M, Martina K, Canaparo R et al. Surface modification and cellular uptake evaluation of Aucoated Ni80Fe20 nanodiscs for biomedical applications. Interface Focus. 2016; 6 (6). DOI: 10.1098/rsfs.2016.0052. 